\title{
LÍNGUA \\ POLONESA \\ NO BRASIL \\ EM TEMPOS DE \\ PANDEMIA: \\ NOVAS \\ POSSIBILIDADES \\ E LIMITAÇÕES
}

\section{LENGUA POLACA EN BRASIL EN TIEMPOS DE PANDEMIA: NUEVAS POSIBILIDADES Y LIMITACIONES}

\author{
POLISH LANGUAGE IN BRAZIL IN PANDEMIC TIMES: NEW POSSIBILITIES AND \\ LIMITATIONS
}

\author{
Karolina Bielenin-Lenczowska* \\ Universidade de Varsóvia
}

Sônia Eliane Niewiadomski**

Universidade Estadual do Centro-Oeste

RESUMO: O presente artigo objetiva mapear e analisar as iniciativas desenvolvidas pela comunidade brasileira de ascendência polonesa no Paraná, em prol da preservação da cultura e manutenção do polonês como língua de herança durante a pandemia do vírus SARS-CoV-2. A estratégia de utilizar o ambiente virtual para minimizar os impactos de transmissão da doença tem se mostrado a melhor alternativa até o momento. Novas oportunidades de contatos linguísticos e culturais surgiram, mas também há limitações relacionadas à falta de interação social na modalidade presencial. Como conceito teórico central propomos a noção de língua de herança para o sistema linguístico falado por brasileiros de ascendência polonesa há mais de um século, transmitido de geração em geração e usado, principalmente, no ambiente familiar. O material empírico que esse estudo dispõe foi obtido de

\footnotetext{
* É antropóloga social e linguista, professora do Instituto de Etnologia e Antropologia Cultural da Universidade de Varsóvia; foi professora visitante no Programa de Pós-Graduaça em Linguística da Universidade Federal de Santa Catarinaentre2019e2021.E-mail:k.bielenin@gmail.com 
pesquisas etnográficas, descritiva e sociolinguística, de campo e observações de atividades realizadas nas modalidades remota e presencial no contexto pandêmico.

PALAVRAS-CHAVE: Língua de herança. Diáspora polonesa. Pandemia. Estratégias. Atividades Online.

RESUMEN: Este artículo tiene como objetivo mapear y analizar las iniciativas desarrolladas por la comunidad brasileña de ascendencia polaca en Paraná, a favor de la preservación de la cultura y el mantenimiento del polaco como lengua heredada durante la pandemia de SARS-CoV-2. La estrategia de utilizar el entorno virtual para minimizar los impactos de la transmisión de la enfermedad ha demostrado ser la mejor alternativa hasta ahora. Han surgido nuevas oportunidades de contactos lingüísticos y culturales, pero también existen limitaciones relacionadas con la falta de interacción social en la modalidad presencial. Como concepto teórico central, proponemos la noción de lengua heredada para el sistema lingüístico hablado por brasileños de ascendencia polaca hace más de un siglo, transmitido de generación en generación y utilizado principalmente en el entorno familiar. El material empírico disponible en este estudio se obtuvo a partir de investigaciones de campo etnográficas, descriptivas y sociolingüísticas y observaciones de actividades realizadas en modalidades remotas y presenciales en el contexto pandémico.

PALABRAS CLAVE: Lengua heredada. Diáspora polaca. Pandemia. Estrategias. Actividades virtuales.

ABSTRACT: This article aims to map and analyze the initiatives developed by the Brazilian community of Polish origin in Paraná, in favor of the preservation of the culture and maintenance of Polish heritage language during the SARS-CoV-2 virus pandemic. The strategy of using the virtual environment to minimize the impacts of disease transmission has proven to be the best alternative so far. New opportunities for linguistic and cultural contacts have emerged, but there are also limitations related to the lack of social interaction in face-to-face encounters. In this paper we propose as a central theoretical concept, the notion of heritage language understood as a linguistic system spoken by Brazilians of Polish descent for over a century, transmitted from generation to generation and used mainly in the family environment. The empirical material for this study was obtained from ethnographic, descriptive and sociolinguistic field research and observations of activities carried out online and offline in the pandemic context. KEYWORDS: Heritage Language. Diasporic community. Pandemic. Strategies. Online activities.

\section{INTRODUÇÃO}

No dia 11 de março de 2020, a Organização Mundial da Saúde declarou a COVID-19, doença causada pelo novo coronavírus, denominado SARS-CoV-2, como pandemia. É considerada como um dos maiores desafios que os seres humanos já vivenciaram, vitimando centenas de milhares de pessoas (AMIRI; AKRAM, 2020).

A pandemia de COVID-19 representa uma ameaça de origem biológica, mas também impede a transmissão de línguas de herança e línguas minoritárias de uma geração para a outra. A alta taxa de mortalidade das pessoas idosas pode desencadear num "linguicídio" (SKUTNABB-KANGAS; BUCAK, 1996) na crise sanitária que o mundo está enfrentando. Desde o início da pandemia, surgiram estudos que trazem dados e discorrem acerca de ameaças às línguas minoritárias em nível global. Pesquisas mostram violência estrutural contra grupos subalternos e menos privilegiados (KABEL; PHILLIPSON, 2020) e também analisam situações sociais em que línguas minoritárias e indígenas reduzem drasticamente o número de seus falantes. Isso se deve tanto ao fato de os usuários falecerem, quanto às diversas políticas linguísticas e limitações relacionadas às possibilidades de comunicação e contato entre as pessoas (AKKUŞ, 2021; DAVID; PRANNANSHU, 2021).

No Brasil, desde março de 2020, em função dessa crise sanitária, foram adotadas medidas restritivas de distanciamento social, afetando a vida pública em todos os aspectos. Assim, as pessoas tiveram de ressignificar a maneira como se relacionam, e uma das alternativas para minimizar o impacto do isolamento físico foi a aproximação virtual por meio de inúmeras atividades e de eventos na modalidade remota. 
Nessa perspectiva, este artigo objetiva mapear algumas práticas linguísticas e ações desenvolvidas por organizações diaspóricas, grupos folclóricos, para preservar a cultura e manter a língua dos seus antepassados, bem como algumas instituições que desenvolvem ações, dando visibilidade à língua e à cultura polonesas no Brasil, principalmente no estado do Paraná ${ }^{2}$, em meio à emergência sanitária causada pela pandemia do novo coronavírus.

É importante destacar que no estado do Paraná, mais especificamente no município de Cruz Machado, logo após a chegada dos primeiros colonizadores poloneses, em 1911, eclodiu a epidemia de tifoide. Em pouco tempo, famílias inteiras foram dizimadas pelo tifo que assolou, na época, o Núcleo Colonial Cruz Machado. Estima-se que aproximadamente dez imigrantes, diariamente, eram vítimas fatais dessa terrível doença, a maior tragédia registrada na diáspora polonesa no território brasileiro (NIEWIADOMSKI, 2019). Não há como comparar o surto de febre tifoide ocorrido em Cruz Machado com a atual pandemia, no entanto, gostaríamos de destacar como surgiu a doença e, posteriormente, discorrer sobre alguns pontos em comum.

Os imigrantes poloneses, ao chegarem ao Núcleo Colonial Cruz Machado, foram submetidos a condições precárias, alocados em pequenas casas com até 120 pessoas, chamadas de budka (o número de pessoas variava conforme o tamanho dessas moradias), passando meses em péssimas condições sanitárias, com a esperança de que logo conseguiriam seus lotes de terra (NIEWIADOMSKI, 2019). A falta de planejamento do Serviço de Povoamento do Solo Nacional em relação à recepção e instalação dos poloneses culminou no caos, pois a expectativa era receber em torno de duas mil pessoas, no entanto, as condições da época não permitiam nem a metade desse número. Essas casas se aglomeravam muito próximas umas às outras e, devido às condições, eram propícias ao aparecimento e à proliferação de doenças.

Os surtos de vírus aparecem e se repetem na história da humanidade, e com algumas semelhanças tanto na forma de se encarar os desafios, em função das proporções que tomam, quanto na maneira da propagação e contenção dessas doenças. No entanto, não há como comparar esses dois acontecimentos tocados neste artigo, mas podemos criar alguns paralelos entre ambos os casos. A saber, a gravidade das duas doenças está relacionada com o seu poder de contágio e proliferação, o comportamento do ser humano perante os surtos e a falta de conhecimento em relação aos métodos de prevenção, entre outros; no entanto, este último fator está intrinsecamente ligado ao desenvolvimento da ciência, que evoluiu bastante até o presente. Sendo assim, acerca dessa temática gostaríamos de destacar que, apesar das diferenças biológicas, sociais, temporais ou geográficas, as crises sanitárias compartilham pontos em comum, como, por exemplo, o caos social, a disseminação de informações falsas, o pânico, as mudanças de comportamento e o isolamento social, esse último afetando as práticas linguísticas e culturais.

Atualmente, em meio à crise sanitária, além dos desafios enfrentados, apareceram novas possibilidades de usar e aprender a língua polonesa contemporânea, mesmo com as limitações de praticar e transmitir o polonês falado no contexto brasileiro. Há muitas denominações para se referir ao sistema linguístico, trazido pelos seus ancestrais, que é falado pelos indivíduos de ascendência polonesa, a saber: língua materna, língua de origem, língua dos imigrantes, língua minoritária, língua comunitária, língua de casa, língua étnica, língua brasileira, língua de herança, język polonijny (língua polônica) ou dialekt polonijny (dialeto polônico) (VALDÉS, 1995; FERRAZ, 2007; FISHMAN, 2001; LIPIŃSKA, 2019; DUBISZ, 1997). Neste estudo, preferimos utilizar a noção de "língua de herança" para se referir a esse código linguístico falado por brasileiros de ascendência polonesa há mais de um século, e, ao longo do artigo, será explanada a conceituação de língua de herança.

A transmissão intergeracional de línguas de herança é crucial para a vitalidade das comunidades de fala desses idiomas, especialmente no Brasil, onde essas línguas são minoritárias, pois pertencem a grupos que não são tão prestigiados socialmente e politicamente e não têm apoio institucional no âmbito estadual e federal. Enquanto algumas línguas de imigração e indígenas foram já cooficializadas em nível municipal (MORELLO, 2015), o polonês não tem esse status mesmo nas regiões onde os brasileiros de origem polonesa constituem a maioria.

1 O estado do Paraná recebeu grandes contingentes de poloneses. Também se instalaram nas regiões do Rio Grande do Sul e Santa Catarina, além de estados como São Paulo, Rio de Janeiro e Espírito Santo. Grupos menores e indivíduos ocuparam outros estados do Brasil. 
A língua de herança, neste artigo mais especificamente o polonês, sobrevive e é preservada por meio da transmissão do conhecimento da língua oral de uma geração para a outra nas comunidades interioranas, e sobretudo no ambiente doméstico, repleto de história e de significados para a família (GOCZYŁA FERREIRA, 2019; NIEWIADOMSKI, 2019). No Brasil, o polonês nas áreas urbanas é menos transmitido, segundo Miodunka (2003), pois a língua é menos utilizada nas cidades grandes, contrariamente ao que ocorre no interior, onde os descendentes falam a língua de seus antepassados no dia a dia em casa, no trabalho rural, nas igrejas e nas conversas informais com os amigos; inclusive gerações mais jovens fazem o uso do polonês, ou seja, a língua de herança nas comunidades interioranas é mais preservada.

A língua polonesa foi usada e transmitida pelos imigrantes e seus descendentes, valendo ressaltar, nesse sentido, que foi ensinada e desenvolvida desde o início da imigração. Colônias foram fundadas distantes das cidades grandes e dos centros urbanos, em sua maioria, formando enclaves nacionais e étnicos. Rapidamente, começaram a surgir escolas, igrejas e editoras que eram os centros do ensino e da difusão da cultura polonesa. Portanto, apesar de várias circunstâncias desfavoráveis, muitos elementos dos costumes e das tradições sobrevivem até hoje. Isso resulta, dentre outros fatores, de eventos realizados nas comunidades e do contato com os vizinhos, utilizando a língua de herança, e, sem dúvidas, das casas multigeracionais muito próximas ainda existentes - onde, por exemplo, as avós participam mais ativamente da vida e dos cuidados de seus netos e netas.

Os fatores que contribuem ou impedem a transmissão intergeracional do polonês são inúmeros, no entanto, citaremos uma política de silenciamento adotada durante a Era Vargas. O presidente Getúlio Vargas, em virtude da ameaça que representava ao Governo no contexto vigente, proibiu o uso de todas as línguas estrangeiras em ambientes oficiais do território brasileiro, e instituiu o Decreto $n^{\circ}$ 406, de 04 de maio de 1938, conhecido como "Lei da Nacionalização". O Decreto-Lei normatizava as práticas culturais, educacionais e linguísticas dos imigrantes no Brasil, e o principal objetivo era tornar a "população brasileira homogênea" linguisticamente. Algumas pessoas dominavam a habilidade de fala somente na língua materna (língua étnica), e foram obrigadas a aprender a língua portuguesa, conforme o Decreto.

Art. 85. Em todas as escolas rurais do país, o ensino de qualquer matéria será ministrado em português, sem prejuízo do eventual emprego do método direto no ensino das línguas vivas.

$\$ 1^{\circ}$ As escolas a que se refere este artigo serão sempre regidas por brasileiros natos.

$\$ 2^{\circ}$ Nelas não se ensinará idioma estrangeiro a menores de quatorze (14) anos.

$\$ 3^{\circ}$ Os livros destinados ao ensino primário serão exclusivamente escritos em língua portuguesa.

$\$ 4^{\circ}$ Nos programas do curso primário e secundário é obrigatório o ensino da história e da geografia do Brasil.

$\$ 5^{\circ}$ Nas escolas para estrangeiros adultos serão ensinadas noções sobre as instituições políticas do país.

Art. 86. Nas zonas rurais do país não será permitida a publicação de livros, revistas ou jornais em línguas estrangeiras, sem permissão do Conselho de Imigração e Colonização.

Art. 87. A publicação de quaisquer livros, folhetos, revistas, jornais e boletins em língua estrangeira fica sujeita à autorização e registro prévio no Ministério da Justiça. (BRASIL, 1938)

A prática de uma língua minoritária pode ser proibida abertamente e diretamente por meio de leis, tortura e ameaças, e tal medida é conceituada como "linguicídio" (SKUTNABB-KANGAS; BUCAK, 1996).

A política conduzida neste período significou o ensino somente do português nas quatro habilidades e a extinção das escolas étnicas, cujo ensino era em outros idiomas, como o polonês, alemão, italiano, ucraniano e japonês. Essa medida resultou na não manutenção da língua de herança em algumas cidades, principalmente daquelas próximas dos grandes centros urbanos. No entanto, essas línguas eram usadas em contextos não oficiais, no seio das famílias, nas comunidades e nos municípios do interior, sendo transmitidas aos mais jovens, mas somente na modalidade oral (COSTA, 2020). Em certa medida, também, graças à impossibilidade de controle por parte do Estado.

Desde então, as instituições de ensino passaram a não ensinar em outros idiomas, somente no português, e o conhecimento dos códigos escritos passou a ser bem menor. Resquícios dessa política nacionalista exercem grande influência, até hoje, sobre as 
línguas minoritárias no país. A seguir, apresentamos a definição de língua de herança, conceito adotado neste estudo para se referir ao polonês falado no Brasil.

\section{LÍNGUA DE HERANÇA: ABORDAGENS CONCEITUAIS}

O termo Língua de Herança (Heritage Language - HL) foi usado pela primeira vez no contexto canadense para se referir a qualquer língua diferente do inglês e do francês, primeiramente fazendo referência às línguas faladas por povos indígenas ou por imigrantes (CUMMINS, 1991). A definição de língua de herança, doravante LH, foi modificada e ampliada para o contexto australiano para incluir qualquer idioma diferente do inglês (CLYNE, 1991).

Nos Estados Unidos, LH abrange uma população enorme e heterogênea, com origens históricas e culturais variadas. Na década de 1990, o conceito de língua de herança naquele país tornou-se conhecido como uma noção que define claramente a história e a identidade dos falantes de inúmeras línguas. Segundo Fishman (2001), refere-se a qualquer língua dos seus ancestrais, línguas indígenas, coloniais e de imigrantes e, portanto, pode ou não ser o idioma usado regularmente em casa e na comunidade. Devido a essa natureza heterogênea de língua de herança, o conceito tem sido usado na literatura com definições variadas, dependendo da perspectiva envolvida (CUMMINS, 1983; MONTRUL, 2012; BENMAMOUN; MONTRUL; POLINSKY, 2010; POLINSKY, 2008; CARREIRA, 2009; VALDÉS, 2005).

Os pesquisadores Campbell e Peyton (1998) destacam que como língua de herança consideram frequentemente a língua que é utilizada no ambiente familiar, no entanto, há autores que ampliaram o significado do termo e estendem também para o contexto das associações culturais. Ainda na declaração formulada pelo comitê gestor do National Heritage Language Resource Centre da UCLA² $^{2}$, em 2000, destaca-se que a aquisição de uma LH começa no seio familiar, isto é, em casa.

No contexto brasileiro, mas especificamente tratando-se do polonês como LH, para os falantes, a língua é um fator de identificação, simbolizando o pertencimento à cultura dos ancestrais. Os descendentes possuem diferentes graus de domínio da LH e o uso acontece, além do ambiente familiar, nas igrejas, na vizinhança (por exemplo, na roda de chimarrão, um agenciador importante na constituição de relações sociais), nos clubes, no comércio, dentre outros, e, ao mesmo tempo, estão em contato com a língua majoritária, nesse caso, o português. Os falantes de língua de herança podem ter diferentes graus de proficiência e habilidade linguística (MONTRUL, 2013).

Assim, sua presença nas esferas social e educacional (cursos de línguas e eventos relacionados ao idioma e à cultura), e a atuação dos agentes sociais e culturais, sem dúvida, propicia a sua manutenção, bem como fortalece a identidade linguística dos indivíduos de ascendência polonesa.

Sendo assim, precisamos destacar algumas políticas linguísticas que contribuem para o resgate e a expansão do ensino e da aprendizagem de polonês nas comunidades de ascendência polonesa. No entanto, chamamos a atenção para o fato de que, diferentemente do contexto americano, onde há escolas étnicas polonesas, nos dias de hoje, no Brasil, o contato com a língua polonesa no âmbito educacional ocorre somente por meio de cursos de línguas particulares em instituições de ensino, organizações ou associações.

Nos últimos anos, houve um aumento considerável de ensino e aprendizagem de língua polonesa, inclusive cabe citar aqui que, no Rio Grande do Sul, mais especificamente no município de Guarani das Missões, há um dispositivo na Lei Orgânica do Município (Art. 142, II $)^{3}$ que trata acerca do ensino da língua polonesa nas escolas da rede municipal e, já há alguns anos, o polonês faz parte

2 University of California Los Angeles.

3 Art. 142. Das disciplinas ministradas em Escolas Municipais, fica estabelecido o seguinte: I - o ensino religioso, de matrícula facultativa, constituirá disciplina dos horários normais; II - o ensino de Técnicas Agropecuárias, do Cooperativismo, do Associativismo, do Sindicalismo, da Organização Rural, da preservação do 
da grade curricular das crianças. Além dessa iniciativa, destacamos também a implantação do CELEM (Centro de Línguas Estrangeiras Modernas) no estado do Paraná, com o intuito de expandir a oferta gratuita de línguas estrangeiras nos estabelecimentos de ensino da rede pública, tais como: espanhol, francês, inglês, italiano, alemão, japonês, ucraniano, polonês e mandarim. Em 2021, a língua polonesa no CELEM está sendo ofertada somente no Colégio Estadual Santa Cândida, no município de Curitiba.

O objetivo dessas iniciativas é o ensino da língua polonesa contemporânea, ou seja, a variedade standard, como observa GoczyłaFerreira (2019); os materiais didáticos são preparados para ensino do polonês como língua estrangeira e destinados aos estrangeiros que estudam na Polônia. Enquanto isso, a aquisição de uma língua de herança ocorre na infância e o seu conhecimento é frequentemente limitado ao círculo familiar. Isso significa que as competências, incluindo o léxico, se limitam ao domínio da vida doméstica e das relações interpessoais. Esse domínio, entretanto, pode ser muito extenso: por exemplo, o léxico relacionado à agricultura. O ensino e a aprendizagem do polonês para as pessoas de ascendência polonesa devem estar associados à valorização da cultura local dos falantes, e inseridos no contexto da comunidade, que é diferente do país de origem dos antepassados (GOCZYŁA FERREIRA, 2019).

Para entendermos melhor a inserção da língua e da cultura polonesa no território brasileiro, a seção seguinte trata da imigração polonesa no Brasil.

\section{CONTEXTO HISTÓRICO DE IMIGRAÇÃO}

A migração do povo polonês foi motivada, primeiramente, pelas situações difíceis vivenciadas, com a falta de emprego, de terras, com a ausência de legislação agrária, de condições dignas para viver e com um elevado crescimento demográfico. Ainda, era reforçada pela opressão política e cultural (processos de germanização e russificação), incluindo a proibição do uso da língua polonesa em locais públicos, como em igrejas, escolas, universidades, por causa da partilha da Polônia por 123 anos (de 1795 a 1918 o país não existiu oficialmente como estado independente). Ressaltamos que a maior parte dos poloneses que emigraram ao Brasil eram camponeses pobres, submissos aos latifundiários, e a grande maioria não tinha instrução.

É necessário também destacar que a propaganda brasileira para a atração de imigrantes, oferecendo terras a baixo custo e promessas de melhoria de vida, as quais, muitas vezes, criaram lendas sobre o país, impulsionou fortemente os fluxos migratórios da Europa e da Ásia, dos mais diferentes grupos étnicos, como, por exemplo, alemães, italianos, poloneses, japoneses.

O Brasil começou a receber em massa imigrantes poloneses no final do século XIX, mais especificamente no Paraná, em 1871, na região de Pilarzinho, Curitiba. A maioria dos que emigraram aos países da América Latina eram "colonos camponeses" (MAZUREK, 2016, p. 41). Como já mencionado, além do Paraná, os imigrantes ocuparam cidades do Rio Grande do Sul, Santa Catarina, São Paulo, Rio de Janeiro e Espírito Santo, mas houve também pequenos grupos de pessoas que se assentaram em outros estados do Brasil. Os poloneses ocuparam sobretudo as colônias rurais nos estados do sul do país.

Segundo Wachowicz (1999), a abolição da escravatura, em 1888, e a Proclamação da República, em 1889, intensificaram a emigração europeia ao Brasil. A promoção da imigração europeia em massa foi estimulada, sobretudo para substituir o trabalho dos africanos e para "branquear" a população brasileira. No território polonês, por exemplo, houve uma intensa propaganda imigratória pelos agentes "[...] pagos pelo governo brasileiro ou pelas companhias de navegação, passaram a fazer forte propaganda entre os camponeses. A estrutura caótica, as fortes pressões para desnacionalizar as populações polonesas e as altas taxas de crescimento demográfico, facilitaram essa propaganda" (WACHOWICZ, 1999, p. 13).

meio ambiente (ecologia), da memória histórica local, com ênfase à Cultura Polonesa, das regras de trânsito, diluídas do conjunto de disciplinas curriculares vigentes, terão caráter obrigatório; (redação dada pela Emenda nº 01, de 20-09-2001). 
O Paraná foi o estado que mais recebeu imigrantes poloneses, de acordo com a literatura (GLUCHOWSKI, 1927; WACHOWICZ, 1981; MAZUREK, 2016), mas é difícil estimar o número. No final do século XIX, a Polônia não existia como país independente e os imigrantes vieram como cidadãos alemães, russos e austríacos, e poucos documentos pessoais se preservaram. Nas pesquisas de campo, encontramos livros de oração, fotografias, antigos jornais e um altar repleto de imagens de santos, como, por exemplo, Nossa Senhora de Częstochowa, porém poucos documentos de identificação, como passaportes. A maior parte das pessoas entrevistadas não tem conhecimento algum sobre as origens dos seus ancestrais - sabem apenas que estes vinham da Polônia.

A chegada do povo polonês ao Paraná modificou a paisagem cultural e sociolinguística, visível, principalmente, na arquitetura das casas e igrejas e na organização das hortas e dos jardins. Nas comunidades de ascendência polonesa desta pesquisa, observamos que as casas térreas de madeira, pintadas normalmente em azul ou verde, são características dessa paisagem. Telhados inclinados são uma herança dos antepassados que os construíram para se proteger da neve. Há jardins de flores em frente às casas e uma horta nos fundos, com hortaliças que refletem os hábitos alimentares dos descendentes de colonos: batata, cebola, repolho, raizforte, endro, beterraba e pepino. Igrejas com torres altas e campos com plantação de cereais também são características desta paisagem (FOETSCH, 2007).

No entanto, a língua polonesa praticamente não se nota na paisagem linguística, embora seja facilmente audível no âmbito sonoro ${ }^{4}$. Há poucos traços da presença da língua nos nomes das ruas, nos nomes de lojas ou de outros serviços pertencentes aos indivíduos de ascendência polonesa. Além disso, estão presentes nos cemitérios. No entanto, estes são poucos e singulares traços, incomparáveis com a presença da língua polonesa na fala. (BIELENIN-LENCZOWSKA, 2020).

A língua usada pelos interlocutores desta pesquisa é uma língua de herança - o código falado, desenvolvido no Brasil na base das variedades rurais faladas de diferentes regiões da Polônia e em contato com a língua portuguesa e outras línguas locais (GOCZYŁA FERREIRA, 2019; CORBARI, 2012). Trata-se de um sistema linguístico trazido pelos ancestrais há mais de um século, ou seja, não é o mesmo código usado na Polônia atualmente.

Notoriamente, os brasileiros de ascendência polonesa também têm contato com a polonês falado nos dias de hoje na Polônia, principalmente graças à participação em cursos de língua, ensaios de grupos folclóricos e por meio das possibilidades que a Internet oferece atualmente.

\section{PRESSUPOSTOS METODOLÓGICOS}

O material empírico para este artigo vem da uma pesquisa etnográfica, descritiva, sociolinguística e de campo, no estado do Paraná, bem como das nossas observações das atividades remotas e presenciais durante a pandemia.

Pesquisas etnográficas e etnolinguísticas desenvolvidas em distrito Rio Claro do Sul (antiga Colonia Rio Claro), interior do Paraná, desde de 2015 até o presente, se concentram no conceito de patrimônio cultural dos brasileiros de origem polonesa através das práticas linguísticas e alimentares (BIELENIN-LENCZOWSKA, 2020). Foram utilizados métodos etnográficos clássicos, ou seja, entrevistas formais e informais, observações dos participantes acompanhadas pelas notas de campo e análise de materiais visuais. Foram conduzidas entrevistas narrativas com elementos de histórias de vida, em particular com os elementos de biografias linguísticas (GOCZYŁA-FERREIRA, 2019; MIODUNKA, 2003). As entrevistas e conversas informais, em sua maioria, foram realizadas nas casas dos interlocutores em língua polonesa (ou usando várias práticas transidiomáticas, dependendo do tema abordado e das competências linguísticas da pesquisadora e dos entrevistados).

4 Trata-se aqui da paisagem sonora soundscape, definida nas ciências sociais como uma parte da paisagem cultural composta por sons de um determinado lugar: os sons dos animais, dos fenômenos da natureza, os sons advindos dos objetos construídos pelos seres humanos, por exemplo, os meios de transporte ou as ferramentas de trabalho e os sons das pessoas (a saber, falas, sotaques, ato de caminhar ou correr, músicas, etc.) (TORRES; KOZEL, 2010; SAMUELS et al., 2010). 
Durante a pandemia, mantivemos o contato na modalidade remota com os nossos interlocutores, realizamos entrevistas e conversas informais online (via videoconferências), observações e participação em grupos de WhatsApp, eventos organizados pelas comunidades locais em redes sociais, como o Facebook. Esses sites e plataformas online consistiram em fonte de material empírico e ferramenta de comunicação. Além disso, foram realizadas entrevistas com membros de três famílias e observação durante a Páscoa de 2021, em Rio Claro. Para este artigo, usamos dados de oito entrevistas, realizadas entre março de 2020 e maio de 2021, e observações de atividades online de quatro organizações diaspóricas e do Núcleo de Estudos Eslavos da Unicentro (maiores detalhes estão na quinta seção deste artigo), também realizadas neste período.

A investigação, empreendida em 2019 e 2020, contou com a coleta de dados de fala em língua polonesa de brasileiros com ascendência polonesa para a realização de descrição linguística, mais especificamente no município de Cruz Machado, e mostrou que os falantes mantêm um sistema estável da língua de herança, aquele trazido pelos seus ancestrais. Por meio das fichas sociais simples, que versaram sobre faixa etária, gênero, uso linguístico - contexto e níveis de competência da(s) língua(s), ambiente de aquisição, escolaridade e profissão (NIEWIADOMSKI, 2019; NIEWIADOMSKI; COSTA, 2020), é possível ilustrar o uso da língua de herança e das práticas culturais.

Para tanto, descrevemos no que segue as práticas linguísticas e culturais em tempos de pandemia da comunidade brasileira de ascendência polonesa no Paraná.

\section{CONTEXTO DE USO DO POLONÊS EM TEMPOS DE PANDEMIA: NOVAS ESTRATÉGIAS E LIMITAÇÕES}

Os migrantes e representantes de diferentes diásporas há muito usam novas tecnologias para se comunicarem, fortalecerem os laços familiares e de amizade, adquirirem novas habilidades ou participarem da vida política (BERNAL, 2006; PATZER, 2015). As organizações, entidades e comunidades locais participam de atividades de mídia social, gravam materiais audiovisuais ou coletam arquivos digitais. No entanto, nunca foi como agora, que, há mais de um ano, devido à disseminação do vírus SARS-CoV-2 e às restrições relacionadas, organizações diaspóricas transferiram suas atividades completamente para a modalidade remota. Inviabilizados para se reunirem fisicamente, as associações, as entidades e os grupos folclóricos organizam suas ações e ensaios online e propõem várias outras atividades que podem ocorrer de maneira virtual.

Apresentamos algumas iniciativas e práticas de entidades e organizações diaspóricas durante a pandemia, evidenciando que novas oportunidades e estratégias surgiram como alternativa para estabelecer, ampliar e manter contato entre a diáspora e a Polônia e, sobretudo, com a língua e a cultura polonesas.

Escolhemos quatro organizações e o Núcleo de Estudos Eslavos da Unicentro para ilustrar as atividades na modalidade remota da diáspora polonesa no Brasil. Inicialmente, apresentamos brevemente cada uma dessas entidades e, em seguida, examinamos as ações desenvolvidas virtualmente. No entanto, houve várias outras iniciativas de organizações e entidades no estado do Paraná que não mencionaremos.

O mais antigo é o grupo folclórico Karolinka, de São Mateus do Sul, fundado em 1992. No início, era um pequeno conjunto associado à BRASPOL local (fundada em 1991) e à organização juvenil GENSMA (Geração Nova Sãomateuense) - atualmente é um grupo folclórico com muitos sucessos em festivais para adultos e crianças, além de um coral no qual são organizadas aulas de língua polonesa.

A segunda associação que observamos é Mazury, fundada em 1993, pela BRASPOL, inicialmente como "Grupo Folclórico de Mallet"; a denominação Mazury foi adotada posteriormente. Embora o objetivo do grupo seja preservar e manter as tradições polonesas (e da diáspora polonesa) no Brasil, como diz o slogan atual, Mazury é "muito mais que folclore". Desde o ano de 2020, a equipe coleta arquivos relacionados à história dos imigrantes de Mallet, objetivando realizar pesquisas etnográficas e 
demográficas, publicações e aprendizagem do polonês. O seguinte grupo folclórico observado é Kraków, fundado em 2007, no distrito de Rio Claro do Sul, no município de Mallet.

Além dos grupos folclóricos, também analisamos as ações do Clube Literário Władysław Reymont (em polonês, Klub Literacki im. Władysława Reymonta), que atua no município de União da Vitória desde agosto de 2019. A entidade reúne poloneses, pessoas de ascendência polonesa e todos os simpatizantes da cultura polonesa, com intuito de realizar atividades focadas em cinco temáticas: estudos literários e identidade, língua e cultura polonesa, arte e cultura polonesa, turismo da diáspora polonesa e expressões culturais. O Clube Literário Władysław Reymont colabora com o Observatório Polonês da Universidade Estadual do Paraná, em União da Vitória. Trata-se de um programa de extensão universitária que integra professores, pesquisadores e estudantes do campus à comunidade de poloneses, descendentes e interessados na cultura polonesa da região.

Como já mencionamos, a utilização da mídia, especialmente das redes sociais, não é algo novo para as organizações e comunidades de migrantes e da diáspora. As associações e entidades que abordamos nesse estudo há algum tempo possuem suas páginas próprias nas redes sociais, seus endereços eletrônicos e ricos arquivos audiovisuais digitais. No entanto, o contexto da crise sanitária impulsionou a utilização de inúmeras ferramentas digitais e colocou suas funções em evidência, revelando que o espaço digital serve para, além de se comunicar, se relacionar, e não necessariamente para se isolar, mas, sobretudo, para se conectar e se aproximar virtualmente.

Portanto, há um certo crescimento e certa ampliação de ações em prol da língua e da cultura polonesas, e nesse atual contexto estão sendo realizadas de uma forma diferente. Apareceram novas iniciativas e novos projetos dos quais se pode participar sem sair de casa.

Nesse sentido, destacamos a seguir uma ação desenvolvida nessa nova modalidade pelo grupo Mazury (GRUPO FOLCLÓRICO POLONÊS MAZURY, 2020) pela ocasião do feriado polonês em comemoração ao Dia da Bandeira e ao Dia da Diáspora Polonesa e dos Poloneses no Exterior, no dia 02 de maio, e ao Dia da Constituição da Polônia, no dia 03 de maio de 2020. O grupo Mazury publicou na sua página do Facebook a seguinte informação: "Os dias 02 e 03 de maio são datas importantes para a comunidade polonesa em todo o mundo. Este ano não pudemos nos encontrar para celebrar estas datas, mas não esquecemos... E não queremos esquecer a nossa história...", e logo transmitiu um curto vídeo, no qual os membros do grupo apresentam a história da presença polonesa no município de Mallet. É importante ressaltar que o vídeo produzido está em português, mas é possível incluir legendas em polonês.

Por sua vez, o coral Karolinka gravou (todos os membros em suas próprias casas) uma canção popular relacionada à comemoração do dia 03 maio (GRUPO FOLCLÓRICO POLONÊS MAZURY, 2020) ${ }^{5}$, intitulada Witaj Majowa jutrzenko. Anteriormente, ainda foram gravadas outras canções e lendas populares da cultura polonesa e, em seguida, enviadas no âmbito da iniciativa "Meu coração polonês", organizada pelo Clube Literário Władysław Reymont. Tais gravações foram compartilhadas e comentadas nas redes sociais do grupo Karolinka e nos grupos de WhatsApp.

No mês de maio de 2020 foi possível verificar um grande engajamento das organizações, das entidades e dos grupos folclóricos de vários lugares do Brasil na modalidade virtual. Entre 22 a 24 de maio realizou-se o Primeiro Encontro Online de Grupos Folclóricos Poloneses. Esse evento contou com a participação de dezesseis grupos do Brasil, da Argentina e da Polônia, incluindo Karolinka, Mazury e Kraków que são o foco da nossa pesquisa. As apresentações dos dançarinos foram transmitidas via Facebook, compartilhadas em vários grupos do WhatsApp e amplamente comentadas pela comunidade polonesa.

Outra ação realizada nessa nova modalidade, em 2020 e 2021, é o projeto Moje polskie serce (Meu coração polonês), proposto pelo historiador Kobelinski da UNESPAR. Trata-se de uma iniciativa que reúne indivíduos de ascendência polonesa no Sul do Brasil, coordenada pelo Clube Literário Władysław Reymont, objetivando “[...] relembrar lugares de memórias que hoje não podem ser

5 Dia 3 de maio comemora estabelecimento de constituição polonesa de 1791. 
visitados e coletar informações da comunidade sobre a epidemia de tifo ocorrida na colônia de Cruz Machado - PR, em 1911, e a atual epidemia de COVID-19"(HISTÓRIA NOS ESPAÇOS PÚBLICOS, 2020). Durante a epidemia da tifoide, em pouco tempo famílias inteiras foram dizimadas por essa doença que assolou, na época, o Núcleo Colonial Cruz Machado.

As atividades propostas por Moje polskie serce são semanais e diversificadas, assim, apontamos algumas ações dos membros: a) interação no grupo WhatsApp, compartilhando, entre outros, músicas gravadas em polonês, fotos e vídeos de apresentações folclóricas, ou, por exemplo, de festividades do Natal e da Páscoa (Święconka - benção de alimentos para serem consumidos no domingo da Páscoa); b) organização de palestras e seminários, intitulados "Diálogos"; c) publicação de livros na versão digital, um deles tratando da culinária polonesa e das tradições da Páscoa e do Natal na Polônia.

A seguir, citamos uma ação realizada em meados de junho de 2020, também na modalidade remota; a vice-presidente do clube postou as seguintes informações em português para os participantes do grupo do WhatsApp:

Caros amigos, hoje estamos iniciando um novo tópico no projeto "Moje polskie serce", que diz respeito à culinária polonesa. Nós convidamos vocês a compartilhar receitas e histórias relacionadas à comida polonesa. Também encorajamos a promover pessoas da região que produzem deliciosos bolinhos, pães, sopas, bolos, etc. Poloneses de Paulo Frontin, São Mateus do Sul, Itaiópolis, Rio Claro do Sul, Florianópolis e Colônia Murici colaboram conosco neste projeto. Abaixo postamos dois lindos vídeos mostrando a Dona Maristela com sua receita de bolinhos e a Sra. Rosa Kazmierczak de Rio Claro do Sul com uma receita de piernik. Até o final de junho, sem pressa vamos conversar, trocar receitas, promover e solicitar pratos poloneses. Fotos e vídeos são muito apreciados!

O produto final da ação foram inúmeras fotos e vídeos relacionados à cozinha polonesa enviados pelos participantes. As conexões das culinárias polono-brasileiras são muito interessantes nas receitas compartilhadas, pois refletem as práticas culturais dos brasileiros de ascendência polonesa já pertencentes à cultura brasileira. Na receita de pierogi, um prato típico para a comunidade de ascendência polonesa no Brasil, propõe-se o recheio de goiabada (na Polônia a goiabada não faz parte da culinária) e, nos pãezinhos, forra-se a assadeira com folhas de bananeira (na Polônia não há cultivo de banana, por questões climáticas). A receita dos pãezinhos de trigo com batatas é transmitida na família Chojnacki de Paulo Frontin há gerações. Já Cecília, da Colônia Murici, compartilhou a receita de pierogi doce, dizendo o seguinte: "Vou fazer com banana. É um perfeito casamento entre a Polônia e o Brasil." (CLUBE LITERÁRIO WŁADYSŁAW REYMONT, 2020). Pratos típicos e tradicionais (WOORTMANN, 2007) são adaptados aos sabores e às possibilidades locais, ao mesmo tempo, não perdem o valor de ser considerados "pratos típicos poloneses".

Em junho de 2020, aconteceram outras atividades com os membros do grupo folclórico Kraków, de Rio Claro do Sul. Naquele mês, os integrantes receberam, da paróquia local, a "Casa do povo"; trata-se de uma das casas mais antigas que existem em Rio Claro do Sul. Após a crise sanitária, esse local poderá ser utilizado para os ensaios do grupo.

Em função disso, a coordenadora da equipe propôs uma ação interessante, na modalidade virtual, ligada a essa relíquia: “A Casa do Povo abrigou vários eventos da comunidade de Rio Claro do Sul, bailes, apresentações, teatros, ensaios e muitos encontros. Conte para nós a sua história também, pretendemos transformar em um documentário, para a preservação da história de Rio Claro do Sul". A postagem recebeu muitos comentários de pessoas que mencionam a sua participação ou a de seus pais nessas inúmeras festividades, e que concordam em contribuir para a efetivação deste documentário.

Outra iniciativa significativa para a região onde os participantes da nossa pesquisa estão inseridos trata-se da Universidade Estadual do Centro-Oeste (UNICENTRO), por meio do Centro de Línguas (CEL) e do Núcleo de Estudos Eslavos (NEES) ${ }^{6}$, que organizou na segunda metade de 2020 um curso de extensão intitulado "Smacznego! Conhecendo a língua e a cultura polonesa

6 Desenvolve ações de extensão com o objetivo de promover a visibilidade da cultura polonesa e ucraniana, mapeando os aspectos culturais e linguísticos do sudeste do Paraná. 
através da culinária”. Esse projeto objetivava sensibilizar, primeiramente, a comunidade interna e externa de abrangência da Unicentro para o aprendizado da língua polonesa nos cursos ofertados pelo Centro de Línguas da Unicentro, campus Irati. No entanto, pela dimensão que essa iniciativa tomou, ampliou-se as inscrições para o público em geral (de diversas cidades do Brasil) e as práticas ocorreram via transmissão no Youtube. Nessa ação, o público participante conheceu o vocabulário básico referente à culinária de uma maneira lúdica e prazerosa, e alguns pratos regionais e típicos da culinária da Polônia e da diáspora polonesa na região de abrangência da Unicentro. A ação contou com a parte prática também, assim os inscritos puderam, durante o curso (ao vivo), preparar dois pratos e, em seguida, enviar fotos e vídeos do produto final aos organizadores.

Além das ofertas dos cursos de língua polonesa na modalidade remota durante o ano de 2020 e no primeiro semestre do ano acadêmico de 2021, em março de 2021 foi organizada uma oficina de decoração de ovos da Páscoa Polonesa. A transmissão ocorreu por meio da plataforma Zoom e o público inscrito era de diversas localidades do Brasil. Neste dia, a oficina foi conduzida por uma artesã de ascendência polonesa e, assim como a iniciativa anterior, esta também contou com a parte prática.

As ações realizadas por grupos, associações folclóricas e instituições de ensino, bem como a comunicação mediada pela tecnologia, destinam-se principalmente às pessoas jovens, pois é o público que mais utiliza as redes sociais, que faz o uso das ferramentas de Tecnologias de Informação e Comunicação para o aprendizado de línguas e para a interação social, incluindo a participação em grupos de WhatsApp. No entanto, não fica restrito somente a essa faixa etária; devido ao avanço do universo digital, ligado às necessidades dos seres humanos, as pessoas mais velhas também fazem uso de plataformas, aplicativos e redes sociais. No entanto, percebemos que não é tão comum a comunidade jovem de ascendência polonesa fazer o uso do polonês como língua de herança. A sua comunicação, tanto na escrita como na fala, é predominantemente na língua portuguesa. O contato com o polonês acontece através de filmes, de posts nas redes sociais ou de cursos na modalidade remota de língua polonesa, mas é com a variedade contemporânea, ou seja, standard.

Na comunidade, onde a língua polonesa de herança é falada no cotidiano, a pandemia limitou os contatos pessoais, especialmente entre as pessoas idosas. Nesses locais, as missas (às vezes em polonês) e os eventos festivos são ocasiões para se comunicar na língua de herança, pois são momentos em que as famílias e os vizinhos interagem. Desde março de 2020, estes encontros estão limitados porque as igrejas estão fechadas, as festas canceladas, e muitas pessoas estão com medo de sair de casa e respeitando as restrições vigentes.

Os eventos festivos religiosos, como, por exemplo, missas e outras celebrações, estão sendo transmitidos por meio de websites das igrejas e pelas redes sociais. Em Curitiba, no Memorial Polonês (Bosque do Papa), por exemplo, a Święconka, tradicional benção de alimentos, festividade da Páscoa realizada no Sábado de Aleluia, considerada um dos mais importantes rituais religiosos para os poloneses e seus descendentes, foi realizada em sistema drive-thru, respeitando o protocolo de distanciamento social.

Em Rio Claro e em algumas cidades menores, a Święconka foi realizada presencialmente na igreja e nas capelas das comunidades no interior e, além disso, a cerimônia foi gravada e transmitida pelas redes sociais. Esta foi a ocasião de encontrar os amigos e vizinhos, respeitando os protocolos de distanciamento e de uso de máscaras.

Nas conversas perto da igreja e depois nos quintais das casas, soubemos que em muitas famílias os encontros pessoais foram bastante limitados, inclusive alguns dos interlocutores informaram que os netos que moram nas cidades não têm visitado os avós no campo há meses, isso não significa, no entanto, que os contatos familiares foram cortados, mas estão sendo mediados pela tecnologia. Como nas descrições de contatos das famílias de migrantes transnacionais (cf. PATZER, 2015), os membros interagem por meio do telefone e até mesmo sentam-se “juntos” à mesa no almoço de domingo. Porém, o português foi a principal língua falada nessas reuniões mediadas por dispositivos (computador e/ou celular). Da mesma forma, apenas o português é usado nas mensagens escritas enviadas aos amigos, vizinhos e familiares. As únicas situações de contatos familiares na modalidade remota em que encontramos o uso da língua polonesa refere-se ao envio de mensagens de Natal e Páscoa ou às gravações com canções polonesas. 
A transmissão da língua e dos muitos elementos da cultura polonesa ou polono-brasileira é realizada através dos encontros presenciais, das relações com os vizinhos na vida cotidiana. Às vezes, esses são os únicos momentos em que os jovens que não dominam a língua de herança têm a oportunidade de ouvir as avós, sejam só palavras, sons ou situações lembradas durante as quais um membro da família fala polonês. Uma das interlocutoras comentou que tem a língua polonesa na sua memória auditiva e que ela lembra a sua avó e as suas tias falando polonês. Este tipo de contato ou de transmissão de idioma não pode ser mediado pela tecnologia, pois trata-se de uma relação diária, física e relacionada às atividades cotidianas, como cozinhar juntos, tomar chimarrão ou trabalhar na agricultura.

\section{CONSIDERAÇÕES FINAIS}

Para concluir, é importante destacar que, embora a modalidade remota apresente limitações bastante específicas, revelou-se, como observado na pesquisa, muito necessária no atual momento que estamos vivenciando. É preciso cumprir as medidas de distanciamento e isolamento físico, portanto, não há como realizar os tradicionais eventos e atividades da comunidade diaspórica (missas, festividades, entre outros), os encontros e ensaios dos grupos folclóricos, nem ter contato físico com os vizinhos (hábito de tomar chimarrão, compartilhando a cuia e conversando em polonês); em síntese, não há como viver como antes da pandemia. Por isso, as comunidades buscaram alternativas para minimizar os impactos causados em todos os aspectos da vida em sociedade, e o ambiente virtual ficou reconhecido como grande aliado nessas práticas e iniciativas.

A utilização da tecnologia já fazia parte da rotina da diáspora polonesa, bem como de outras diásporas e comunidades de migrantes no mundo todo há algum tempo, no entanto, até então a maioria estava habituada a fazer o uso da modalidade virtual apenas como mais um aparato de comunicação básica, não como o único meio para promover a cultura polonesa local e tentar manter o contato com a língua polonesa, como acontece durante a crise sanitária.

Sendo assim, com o presente estudo, constatamos que, em muitas esferas, a língua polonesa se desenvolveu e as atividades na modalidade remota possibilitaram a participação de pessoas que vivem em diferentes lugares, inclusive nos dois lados do Atlântico. Ao mesmo tempo, isso se aplica, principalmente, à língua polonesa standard, pois se trata de palestras ou cursos de línguas. No entanto, a língua de herança, falada e transmitida de gerações em gerações, especialmente pelas mais velhas, sofre muito mais limitações, assim como a família e os seus contatos e as relações na vizinhança. O momento é mesmo desafiador, e as organizações e as entidades envolvidas buscam alternativas e estratégias para a manutenção da língua e da cultura dos antepassados.

\section{REFERENCIAS}

AKKUŞ, M. COVID-19 Pandemisi (Karasalgın) ve Tehlike Altındaki Türk Lehçeleri: Küresel Karasalgın, Dilkırımı (linguicide)Tetikler mi?. Tehlikedeki Diller Dergisi, v. 11, n. 18, p. 158-174, 2021.

AMIRI, S. A.; AKRAM, M. COVID-19: The Challenges of the Human Life. Social Work and Social Sciences Review, v. 1, n. 1-17, 2020 .

BENMAMOUN, A.; MONTRUL, S.; POLINSKY, M. Prolegomena to heritage linguistics. University of Illinois at UrbanaChampaign and Harvard University, 2010.

BIELENIN-LENCZOWSKA, K. A paisagem sócio-linguística: a política, a diversidade e a migração no espaço público. Fórum Linguístico, v. 17, n. 4, p. 5275-5291, 2020.

BRITON, D.; KAGAN, O.; BAUCKUS, S. Heritage Language Education: A New Field Emerging. New York: Routledge, 2008. 
BERNAL, V. Diaspora, cyberspace and political imagination: the Eritrean diaspora online. Global Networks, v. 6, n. 2, p. 161-179, 2006.

BRASIL. Decreto-Lei no 406, de 4 de maio de 1938. Dispõe sobre a entrada de estrangeiros no Brasil. Coleção de Leis do Brasil 1938.

CAMPBELL, R.; PEYTON, J. K. Heritage language students: A valuable language resource. The ERIC Review, v. 6, n. 1, p. 38-39, 1998.

CLYNE, M. G. Community languages: The Australian experience. New York: Cambridge University Press, 1991.

CLUBE LITERÁRIO WŁADYSŁAW REYMONT, 2020. Facebook: @clubeliterariowladyslawreymont. Disponível em: https://www.facebook.com/clubeliterariowladyslawreymont/videos/341146066868106. Acesso em: 24 jun. 2020.

CORBARI, C.C. Crenças e Atitudes Linguísticas de Falantes de Irati (PR). SIGNUM: Estudo de Linguagem, Londrina, v. 15, n. 1, p. 111-127, 2012.

COSTA, L.T. Panorama da língua polonesa falada no interior do Paraná: dados do VARLINFE. Revista X, v. 15, n. 6, p. 87-99, 2020 .

CUMMINS, J. Heritage language education: A literature review. Toronto: Ministry of Education, 1983.

CUMMINS, J. Introduction. The Canadian Modern Language Review, v. 4, n. 47, p. 601-605, 1991.

DAVID, M.; PRASANNASHU, P. COVID-19 Pandemic and Endangered Languages. IARS' International Research Journal, Victoria, v. 11, n. 1), p. 03-04, 2021.

DUBISZ, S. Język polski poza granicami kraju. Opole: Instytut Filologii Polskiej Uniwersytetu Opolskiego, 1997.

FERRAZ, A. P. O panorama lingüístico brasileiro: a coexistência de línguas minoritárias com o português. Filologia E Linguística Portuguesa, n. 9, p. 43-73, 2007.

FISHMAN, J. A. 300-plus years of heritage language education in the United States. In: PEYTON, J. K.; RANARD, D. A.; MCGINNIS, S. (ed.). Heritage languages in America: Preserving a national resource. Washington/McHenry: Center for Applied Linguistics \& Delta Systems, 2001. p. 81-97.

FOETSCH, A. A. Paisagem, cultura e identidade: os poloneses em Rio Claro do Sul, Mallet (PR). Caminhos De Geografia, n. 21, v.21, p. 59-72, 2007.

GLUCHOWSKI, K. Os poloneses no Brasil: Subsídios para o problema da colonização polonesa no Brasil. Porto Alegre: Rodycz \& Ordakowski Editores, 2005 [1927].

GOCZYŁA FERREIRA, A. Nauczanie języka polskiego w polskiej kolonii w Brazylii - studium przypadku. Polonistyka. Innowacje, n. 10, p. 59-78, 2019. 
GRUPO FOLCLÓRICO POLONÊS MAZURY. História Polonesa em Mallet. 2020. Facebook: @GrupoMazury .Disponível em: https://www.facebook.com/GrupoMazury/videos/1866119716856550. Acesso em: 04 jun. 2020.

HISTÓRIA NOS ESPAÇOS PÚBLICOS, 2020. Meu coração polonês: memórias da reclusão! (My Polish heart: memories of seclusion!). 1 vídeo. Publicado em 24 abr. 2020. Disponível em: https://www.youtube.com/watch?v=ZaITN9TSzY4. Acesso em: 22 maio 2020.

KABEL, A.; PHILLIPSON, R. Structural violence and hope in catastrophic times: from Camus' The Plague to Covid-19. Race and Class, v. 62, n. 4, p. 3-18, 2021.

LIPIŃSKA, E. Język polonijny czy języki polonijne? Postscriptum Polonistyczne, v. 2, n. 24, p. 189-204, 2019.

MAZUREK, J. Polônia e seus emigrados na América Latina (até 1939). Goiânia: Espaço Acadêmico, 2016.

MIODUNKA, W. T. Bilingwizm polsko-portugalski w Brazylii. Kraków: Universitas, 2003.

MORELLO, R. Leis e línguas no Brasil. O processo de cooficialização e suas potencialidades. Florianópolis: IPOL, 2015.

MONTRUL, S. Is the heritage language like a second language? EUROSLA Yearbook, v. 12, p. 1- 29, 2012.

MONTRUL, S. Bilingualism and the Heritage Language Speaker. In: BHATIA, T.; RITCHIE, W. C. (ed). Second edition. The Handbook of Bilingualism and Multilingualism. Malden/Oxford: Wiley-Blackwell, 2013. p. 168-189.

MONTRUL, S. The Acquisition of Heritage Languages. Cambridge: Cambridge University Press, 2016.

NIEWIADOMSKI, S. Aspectos sonoros da língua polonesa falada em Cruz Machado no Paraná. 2019. Dissertação (Mestrado em Letras) - Programa de Pós-Graduação em Letras, Universidade Estadual do Centro-Oeste, Guarapuava, 2019.

NIEWIADOMSKI, S.; COSTA, L.T. Os sons fricativos do polonês falado no município de Cruz Machado, no Paraná. Revista X, v. 15, n. 6, p. 184-214, 2020.

POLINSKY, M. Heritage language narratives. In: BRINTON, D.; KAGAN, O.; BAUCKUS, S. (ed.). Heritage language education: A new field emerging. New York: Routledge, 2008. p. 149-164.

PATZER, H. Long-distance care. The practice of sustaining transnational ties by Filipino immigrants in Boston. Tese (Doutorado) Universidade de Varsóvia, Varsóvia, 2015.

SAMUELS, D.; MEINTJES, L.; OCHOA A. M.; PORCELLO T. Soundscapes: Toward a Sounded Anthropology. Annual Review of Anthropology, n. 39, v. 1, p. 329-345, 2010.

SKUTNABB-KANGAS, T.; PHILlIPSON, R. Linguicide and linguicism. In: GOEBL, H. et al. (ed.). Contact linguistics: an international handbook of contemporary research. Handbooks of linguistics and communication science. Berlin: Walter de Gruyter \& Co, 1996. p. 667-675. 
TORRES, M. A.; KOZEL, S. Paisagens sonoras: possíveis caminhos aos estudos culturais em geografia. RA'EGA, Curitiba, n. 20, p. 123-132, 2010.

VALDÉS, G. The teaching of minority languages as academic subjects: Pedagogical and theoretical challenges. The Modern Language Journal, v.3, n. 79, p. 299-328, 1995.

VALDÉS, G. Bilingualism, heritage language learners, and SLA research: Opportunities lost or seized? The Modern Language Journal, v.3, n. 89, p. 410-426, 2005.

WACHOWICZ, R. Aspectos da imigração polonesa no Brasil. Projeções, Curitiba, v. 11, n. 1, p. 48-54, 1999.

WACHOWICZ, R. C. O camponês polonês no Brasil. Curitiba: Gráfica Vicentina, 1981.

WOORTMANN, E. Padrões tradicionais e modernização: comida e trabalho entre camponeses teuto-brasileiros. In: MENASCHE R. (org.). A agricultura familiar à mesa. Porto Alegre: UFRGS, 2007. p. 177-196.

\section{() (1) $\circledast$}

Recebido em 01/05/2021. Aceito em 15/06/2021. 